\title{
Neural Stem Cell Regulation by Adhesion Molecules Within the Subependymal Niche
}

\begin{abstract}
Jose Manuel Morante-Redolat ${ }^{1,2,3}$ and Eva Porlan ${ }^{4,5,6 *}$
${ }^{1}$ Departamento de Biología Celular, Biología Funcional y Antropología Física, Universitat de València, Burjassot, Spain, ${ }^{2}$ Centro de Investigación Biomédica en Red de Enfermedades Neurodegenerativas, Instituto de Salud Carlos III (ISCIII), Madrid, Spain, ${ }^{3}$ Estructura de Recerca Interdisciplinar en Biotecnologia i Biomedicina, Universitat de València, Burjassot, Spain, ${ }^{4}$ Departamento de Neuropatología Molecular, Centro de Biología Molecular Severo Ochoa Consejo Superior de Investigaciones Científicas - Universidad Autónoma de Madrid (CSIC-UAM), Madrid, Spain, ${ }^{5}$ Departamento de Biología Molecular, Facultad de Ciencias, Universidad Autónoma de Madrid, Madrid, Spain, ${ }^{6}$ Hospital La Paz Institute for Health Research (IdiPAZ), Instituto de Salud Carlos III (ISCIII), Madrid, Spain
\end{abstract}

OPEN ACCESS

Edited by:

Aixa Victoria Morales, Cajal Institute (CSIC), Spain

Reviewed by:

Rebecca Hodge, Allen Institute for Brain Science,

United States

Stavros Taraviras,

University of Patras, Greece

*Correspondence:

Eva Porlan

eva.porlan@cbm.csic.es

Specialty section:

This article was submitted to

Stem Cell Research,

a section of the journal

Frontiers in Cell and Developmental

Biology

Received: 09 April 2019

Accepted: 27 May 2019

Published: 12 June 2019

Citation:

Morante-Redolat JM and Porlan E (2019) Neural Stem Cell Regulation by Adhesion Molecules Within the Subependymal Niche.

Front. Cell Dev. Biol. 7:102.

doi: 10.3389/fcell.2019.00102
In the mammalian adult brain, neural stem cells persist in neurogenic niches. The subependymal zone is the most prolific neurogenic niche in adult rodents, where residing stem cells generate large numbers of immature neurons that migrate into the olfactory bulb, where they differentiate into different types of interneurons. Subependymal neural stem cells derive from embryonic radial glia and retain some of their features like apico-basal polarity, with apical processes piercing the ependymal layer, and a basal process contacting blood vessels, constituting an epithelial niche. Conservation of the cytoarchitecture of the niche is of crucial importance for the maintenance of stem cells and for their neurogenic potential. In this minireview we will focus on extracellular matrix and adhesion molecules in the adult subependymal zone, showing their involvement not only as structural elements sustaining the niche architecture and topology, but also in the maintenance of stemness and regulation of the quiescence-proliferation balance.

Keywords: subependymal zone, adhesion molecules, extracellular matrix, neural stem cell, quiescence, niche, adult neurogenesis

\section{THE NEUROGENIC ADULT SUBEPENDYMAL ZONE: A POLARIZED EPITHELIAL NICHE}

In most adult tissues, stem cells dwell in specialized microenvironments called "niches" (Scadden, 2006). In the mammalian adult brain, the subependymal zone (SEZ), is a specialized niche that encompasses a thin layer of cells apposed to the ventricular wall, lined by ependymal cells (EC). Here, neural stem cells (NSC) coexist with their own progeny, supporting niche cells, neighboring blood vessels (BV), and a specialized extracellular matrix (ECM). In addition, they are in contact with the cerebrospinal fluid through a primary cilium at the end of a cytoplasmic process that traverses the ependymal layer through the center of a rosette of ependymocytes, named "pinwheel" (Mirzadeh et al., 2008; Lin and Iacovitti, 2015).

Residing NSC generate large numbers of immature neurons that migrate into the olfactory bulb $(\mathrm{OB})$, to differentiate into several types of interneurons that contribute to refine the processing of olfactory information (Lim and Alvarez-Buylla, 2014; Merkle et al., 2014). The ceaseless production of neurons follows a hierarchical lineage where NSC divide to generate transit amplifying progenitors (TAP) and/or to self-renew. TAP cells can divide a few times more to expand future neural progeny to finally generate migrating neuroblasts (Ortega et al., 2013; Ponti et al., 2013). SEZ 
NSC also contribute to gliogenesis, however, much less productively than to neurogenesis (Menn et al., 2006; Ortega et al., 2013; Sohn et al., 2015), at least in homeostatic conditions.

In early developmental stages, ectodermally derived neural progenitors organize in a neuroepithelial layer surrounding the ventricles, termed the ventricular zone (VZ). Within this polarized arrangement, neuroepithelial cells (and later radial glial cells, RGC), exhibit a characteristic bipolar radial morphology supported by two points of adhesion: at their apical end, neighboring cells adhere to the luminal surface of the VZ through adherens junctions (AJs) mediated mainly by $\mathrm{N}$-cadherin, whereas they remain attached to the subpial ECM via integrinlaminin interactions through their basal end-feet (Meng and Takeichi, 2009; Hirano and Takeichi, 2012). Embryonically, NSC derive from a pool of RGC that become specified at midgestation (Tramontin et al., 2003; Merkle et al., 2004; Kriegstein and Alvarez-Buylla, 2009; Fuentealba et al., 2015; Furutachi et al., 2015), and are as well glial in nature, displaying several ultrastructural characteristics of astrocytes (Doetsch, 2003). Additionally, they retain the apico-basal polarity reminiscent of RGC, with apical processes piercing the ependymal layer, and a basal process extruding onto the traversing $\mathrm{BV}$ and contacting their basal lamina (BL). This cytoarchitecture, with NSC spanning these two important signaling compartments categorizes the SEZ as an epithelial niche (Mirzadeh et al., 2008; Shen et al., 2008; Kokovay et al., 2010) (Figure 1).

\section{THE ECM AS A NICHE COMPONENT}

In most cellular contexts, cell-ECM adhesion mediated by receptors such as integrins provides not only physical support and positioning to the cells, but also initiates cellular responses mainly mediated by phosphorylation states and activities of cytosolic tyrosine kinases, which next regulate other kinases and scaffolding proteins to transduce signals (Morgan et al., 2007). By providing bidirectional connections (intracellularly, by the assembly of cytoskeleton and signaling complexes, and extracellularly, through interactions with ECM elements, and in some cases with counter-receptors on adjacent cell surfaces) integrins force spatial restrictions on signaling and ECM assembly, and so integrate cells with their microenvironment (Humphries et al., 2006). The adult SEZ is rich in ECM molecules, such as fibronectin, laminins- $\beta 1$ and $\gamma 1$, and chondroitin sulfate proteoglycans (Mercier et al., 2002; Marthiens et al., 2010) along with a layer of Tenascin-C that separates the SEZ from the adjacent striatum (Kazanis et al., 2007). Intriguingly, notwithstanding a relevance in embryonic and early postnatal NSC and neural progenitor proliferation and migration (Garcion et al., 2001), in the SEZ Tenascin-C deficiency does not affect NSC nor progeny (Kazanis et al., 2007).

Additionally, a specific feature of the SEZ ECM is the presence of "fractones", conspicuous ECM structures thought to be merely extended formations of the vascular BL, which now seem to be functionally and structurally independent, with their own relevance in the SEZ niche. They may appear either as thin branching lines (stems) or as round deposits (bulbs) frequently popping out at the center of pinwheels or scattered along the inner ependymal wall, and associated with $\mathrm{GFAP}^{+}$-NSC (Nascimento et al., 2018; Sato et al., 2019). SEZ fractones contain laminins, N-sulfate heparan sulphate proteoglycans (HSPG), collagens-I/IV/VI, nidogen-1/2, agrin, netrin-4, and perlecan1 (Mercier et al., 2002; Kerever et al., 2007; Douet et al., 2012; Mercier and Douet, 2014; Sato et al., 2019), and their source has been described as either ependymal (Nascimento et al., 2018) or originating from NSC themselves (Sato et al., 2019). Elimination of laminin- $\alpha 5$ from EC increased activation of NSC (Nascimento et al., 2018) and disrupting integrinbinding activities of laminins specifically in astrocytes (including NSC), decreased the number and size of fractones, although the effects of this disruption on NSC proliferation were not investigated in vivo (Sato et al., 2019). Interestingly, fractones can promote heparin-binding growth factor activity and influence cell proliferation in the SEZ by sequestering basic-FGF and BMP4/7 from the extracellular milleu (Kerever et al., 2007; Douet et al., 2012; Mercier and Douet, 2014).

\section{ADHESION AT THE BASAL END: WHERE NSC MEET THE BLOOD VESSELS AND THEIR BASAL LAMINA}

Around their basal process, RGC secrete a layer of ECM, to form the basement membrane, and transcriptome analyses of fetal human and embryonic mouse VZ, sub-VZ, and cortical plates, revealed elevated expression of genes related to cell adhesion and cell-ECM interactions (collagens, laminins, proteoglycans, and integrins) indicating their functional relevance (Fietz et al., 2012). Deletion of integrin function during brain development promotes process detachment, apoptosis, and altered neurogenesis (Graus-Porta et al., 2001; Campos et al., 2004; Belvindrah et al., 2007; Shen et al., 2008; Loulier et al., 2009; Fietz et al., 2010; Kazanis et al., 2010; Marthiens et al., 2010; Theocharidis et al., 2014; Chou et al., 2018), revealing altogether a structural role of integrin signaling within the niche, and in the maintenance of polarity, regulation of embryonic NSC pools asymmetric cell division, cortical expansion and neurogenesis.

Adult NSC are also polarized, and distinct stem-cell domains have been defined along their radial morphology. The basal domain corresponds to specialized long processes that contact directly BV, and the majority of dividing cells in the SEZ proliferate in the immediacy of BV which, ensheathed by their laminin-rich $\mathrm{BL}$, provide the vascular compartment of the niche (Shen et al., 2008; Tavazoie et al., 2008). In fact, dividing NSC (and TAP) are directly associated with vasculature, establishing cell-ECM contacts with the endothelial BL (Shen et al., 2008). SEZ cells express differential levels of ECM receptors which appear to correlate with their mitotic status, rather than with a cell identity: for instance, quiescent NSC (qNSC) express low levels of $\alpha 6 \beta 1$ integrin, syndecan-1, and lutheran, whereas their levels increase in activated NSC (aNSC) and mitotic TAP (Shen et al., 2008; Kazanis et al., 2010; Morizur et al., 2018).

ECM via integrins regulates SEZ-cells proliferation and stemness, at least within this vascular context. Stromal-derived 


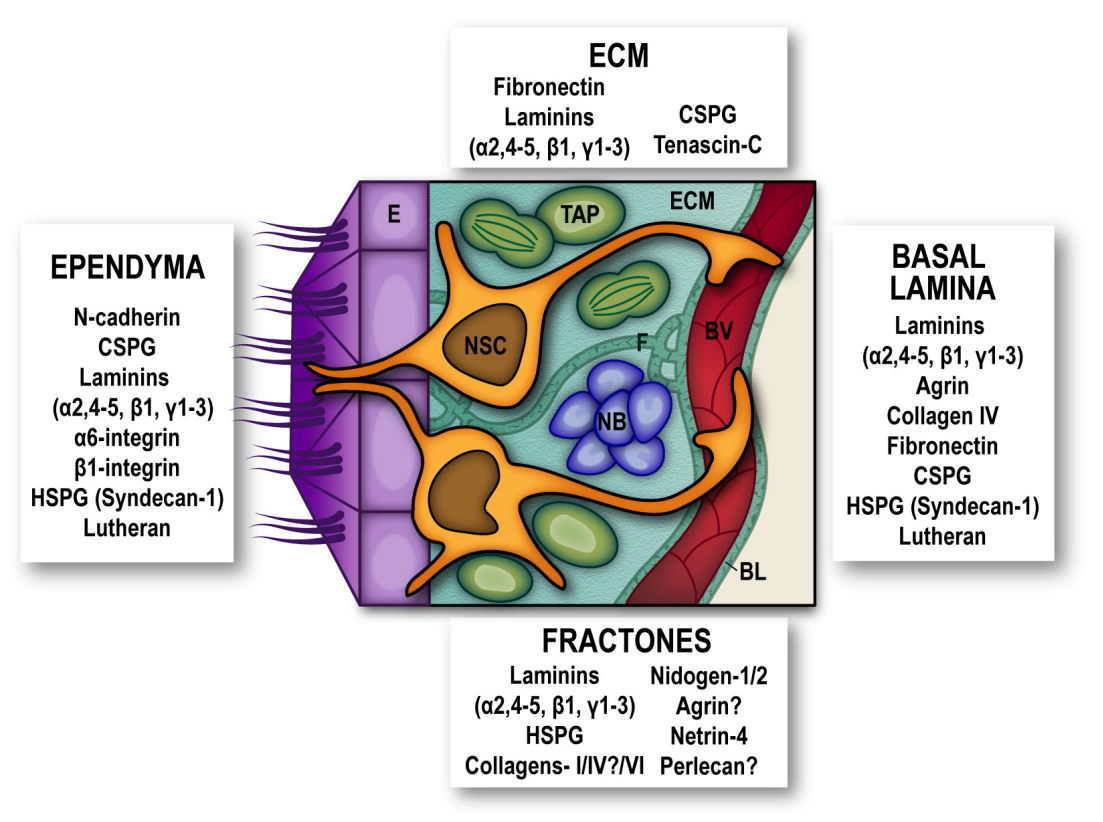

FIGURE 1 | Extracellular matrix and adhesion molecules are SEZ niche components. Schematic representation of the subependymal niche showing cellular populations (multiciliated ependymal cells -E, purple-, neural stem cells -NSC, orange-, transit amplifying progenitors -TAP, green-, neuroblasts -NB, blue- and blood vessels -BV, red-) and specific extracellular matrix proteins and adhesion molecules reported to be present subependymal zone extracellular matrix (ECM), in basal lamina (BL), fractones (F), and ependymal cells. Question marks are present where conflicting reports have been published. For the sake of clarity other niche elements such as microglia, non-neurogenic astrocytes and innervation have been omitted from the schematic. HSPG, heparan-sulfate proteoglycans; CSPG, chondroitin sulfate proteoglycans.

factor 1 (SDF1)- and CXC chemokine receptor 4 (CXCR4) upregulate EGFR and $\alpha 6$-integrin in aNSC and TAP, contributing to homing of SEZ progenitors to endothelial cells and to their proliferation by increasing their binding to laminin (Kokovay et al., 2010). In vitro, endothelial-derived laminin sustains proliferation and stemness of SEZ cells in brain endothelialneurosphere cell co-cultures, process that is dependent on $\alpha 6 \beta 1$-integrin, via activation of the Notch and mTOR signaling pathways (Rosa et al., 2016). On the other hand, loss of integrinlinked kinase (ILK), enhances proliferation by over-activation of JNK (Porcheri et al., 2014). $\beta 1$-integrin signaling suppresses astrocytic differentiation (Pan et al., 2014), and the carbohydratebinding protein Galectin-1 interacts with $\beta 1$-integrin to regulate the number of neural progenitors as well as new migrating neurons. This has a relevant implication on regeneration, as these new-born neurons enhanced recovery from behavioral deficits resulting from brain damage (Sakaguchi et al., 2006, 2010; Ishibashi et al., 2007). Contrasting downstream signals can be elicited by specific integrin ligands; transforming growth factor beta 1 (TGF $\beta 1$ ), an anti-inflammatory cytokine, exerts proneurogenic effects on SEZ NSC regulating a set of genes involved on the integrin pathway (Radice et al., 2015), and $\beta 8$-integrin promotes proliferation of SEZ cells and in migrating neuroblasts, potentially through TGF $\beta 1$ as well (Mobley et al., 2009; Mobley and McCarty, 2011).

Although not considered strictly speaking as "cell adhesion," it is important to highlight that vascular endothelial cells can also provide NSCs with a pro-quiescence environment by means of direct cell-cell contacts of NSCs with BV, since it has been shown that endothelial ephrinB2 and Jagged suppress NSC proliferation while maintaining stemness (Ottone et al., 2014). Also, cell-cell interactions with other niche dweller populations work in a negative feedback loop to prevent NSC exhaustion. Niche-residing non-neurogenic astrocytes, for instance, secrete delta-like homolog (Dlk1) that binds its own membrane-bound isoform expressed in the surface of NSC to regulate their self-renewal (Ferron et al., 2011). Additionally, NSCs and TAPs express surfacebound Notch-ligand Dll1 to sustain quiescence in qNSC that specifically express Notch2 receptor (Kawaguchi et al., 2013; Llorens-Bobadilla et al., 2015).

\section{ADHESION AT THE APICAL END: REACHING THE EPENDYMAL WALL AND BEYOND}

Distance from the EC/ventricle also seems to have a strong role limiting proliferation (Kazanis et al., 2010), indicating that elements involved in the maintenance of topology have functional roles in the SEZ neurogenic activity. According to their conserved apico-basal morphology, NSC directly contact the ependymal layer, with apical processes serving as grips that provide structural integrity. At the tip of the apical processes, a primary cilium pokes out from the ventricle wall serving as an antenna for the NSC (Mirzadeh et al., 2008). 
Embryonic RGC bipolar radial morphology is supported at their apical tip through $\mathrm{N}$-cadherin mediated AJs, to attach to the luminal surface of the VZ and neighboring cells (Hirano and Takeichi, 2012; Miyamoto et al., 2015). Compromised expression of N-cadherin in embryonic NSC leads to VZ/sub-VZ disruption, displacement of NSCs into the CSF, hydrocephalus, atypical neurogenesis and randomization of the intra-cortical structures and formation of periventricular heterotopias (Kadowaki et al., 2007; Gil-Sanz et al., 2014; Guerra et al., 2015; Jossin et al., 2017).

Attempts to inactivate $\mathrm{N}$-cadherin specifically in postnatal/adult NSC have been made and, as in the embryo, $\mathrm{N}$-cadherin-mediated adhesion is paramount to preserve the integrity of the adult SEZ and essential for the maintenance of NSC. hGFAP-Cre mice transgenic strain was used to evaluate the effect of N-cadherin in NSC from the SEZ. However, since both adult NSC and ependymocytes derive from RGC, which activate this promoter during development, unsurprisingly, both populations appeared drastically affected. The mutant displayed severe disassembly of the ependymal barrier concomitant with SEZ hyperplasia and increased proliferation of NSC, revealing that $\mathrm{N}$-cadherin anchors act as quiescence signals (Porlan et al., 2014). In adult mice, acute inactivation of $\mathrm{N}$-cadherin either in the whole SEZ or only in ECs showed an increase in NSC proliferation. In the case of ependymal inactivation, an additional denudation of the ventricle wall sheathing, in line with a previous report in which electroporation of a dominant-negative version of $\mathrm{N}$-cadherin provoked ependymal loss and protrusion of the SEZ cells into the ventricle (Barnabe-Heider et al., 2008). These experiments clearly indicated that $\mathrm{N}$-cadherin does indeed maintain the cytoarchitecture of the adult neurogenic niche and that this is functionally related to the activation status of residing stem cells (Porlan et al., 2014). E-cadherin, on the other hand, is the main component of the zonula adherens in non-neural epithelia, but maybe due to its secondary role in neural tissue, deletion of E-cadherin in the adult SEZ did not result in severe disruption of its cytoarchitecture, although still caused defects on NSC self-renewal (Karpowicz et al., 2009). Likewise, the lateral membrane adaptor protein Ank3 is critical for differentiation of EC and consequently, for neurogenesis (Paez-Gonzalez et al., 2011).

Integrins also contribute to the attachment of apical processes in embryonic RGC (Lathia et al., 2007; Loulier et al., 2009). In the adult SEZ, $\beta 1$-integrin upregulates in NSC that activate to repopulate the niche after a depletion paradigm with antimitotic drugs. Also, injection of functionblocking antibodies in the adult ventricle in homeostasis results in disruption of the ventricular surface, increased TAP proliferation and invasion of neuroblast clusters within the ventricle, though NSC remained unaffected (Kazanis et al., 2010).

Preservation of quiescence and transition into an active proliferating state is an extremely regulated process. Therefore, is not surprising to find that extrinsic and intrinsic factors fine-tune the adhesive properties of the niche to retain stem cells and regulate their activation, adding another layer of complexity to the microenvironment. For example,

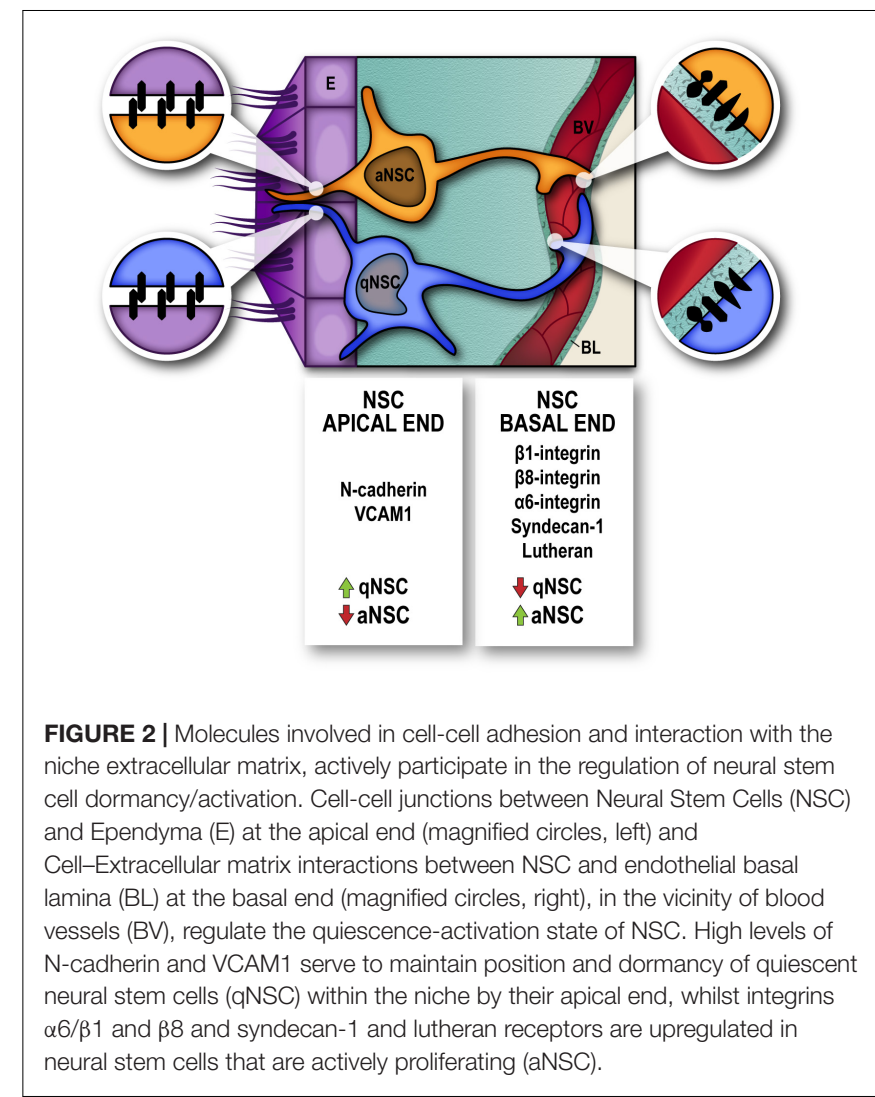

$\mathrm{N}$-cadherin dependent activation of NSC can be modulated by the proteolytic activity of specific proteases, such as Mmp24-MT5 that cleaves $\mathrm{N}$-cadherin to properly activate NSC under physiological and regenerative conditions (Porlan et al., 2014). Furthermore, in experimental demyelination, A Disintegrin and metalloproteinase domain-containing protein 10 (ADAM10) processes $\mathrm{N}$-cadherin in response to an activation signal initiated by EGFR (Klingener et al., 2014) again supporting the idea that dynamical regulation of adhesion to the niche by proteolysis can recruit NSC on demand for active proliferation. Interestingly, MMP12 another matrix metalloproteinase, regulates EC maturation and SEZ output modulating NSC quiescence (Shan et al., 2018).

Vascular Cell Adhesion Molecule-1 (VCAM1) is also highly expressed by NSC, specifically at their end-feet in the center of pinwheels to maintain NSC quiescence. Blocking VCAM1 function severely disrupts the niche structure, affecting ependymal cytoarchitecture and generating loss of pinwheels. This also produces an increase of $\mathrm{OB}$ neurogenesis, further showing that exogenous manipulation of the adhesive properties of the niche could indeed have an impact of neuronal progeny (Kokovay et al., 2012). Interestingly, VCAM1 increases as a response to IL-1 $\beta$, signaling via NOX2-produced reactive oxygen species, to maintain NSC indicating that it can sense the environment, responding to chemokines involved in tissue repair (Kokovay et al., 2012). 


\section{ADHESION AND REGULATION OF QUIESCENCE BY THE NICHE}

Notwithstanding their potential for generating differentiated progeny, NSC display a functional quiescence in adulthood (Fuentealba et al., 2015; Furutachi et al., 2015), and in contrast to other tissues, adult NSC can be found at different states of activation (Daynac et al., 2013; Codega et al., 2014; Mich et al., 2014; Llorens-Bobadilla et al., 2015; Chaker et al., 2016; Kalamakis et al., 2019). Switch from qNSC to aNSC state can be induced by selective elimination of neural progeny (Daynac et al., 2013; Codega et al., 2014; Mich et al., 2014), and quiescence appears to be a mechanism to protect NSC pools throughout life and hence maintain homeostasis and tissue regeneration. Failure to restrict mitotic activation of NSC leads to premature depletion of the niche (Doetsch et al., 2002; Molofsky et al., 2003, 2005, 2006; Kippin et al., 2005; Marques-Torrejon et al., 2013; Porlan et al., 2013), and in the aged brain, NSC quiescence increases in what has been interpreted as a mechanism to avoid full exhaustion (Luo et al., 2006; Bouab et al., 2011; Silva-Vargas et al., 2016; Bast et al., 2018; Kalamakis et al., 2019). In light of all these evidences, the quiescent state of NSC is now considered as an actively regulated condition, in contrast to the classic vision of it being a mere passive quality. Interestingly, the niche appears to play an essential role in the regulation of NSC fate and number by controlling the reversible transition between the quiescent and active NSC compartments (Llorens-Bobadilla and Martin-Villalba, 2017; Basak et al., 2018; Kalamakis et al., 2019).

Many efforts have been made to reveal the molecular signature of qNSC, and strategies to prospectively isolate dormant NSC from the adult SEZ have used a combination of stem cell/progeny markers to analyze the transcriptome of non-proliferative vs. aNCS (Capela and Temple, 2002; Pastrana et al., 2009; Beckervordersandforth et al., 2010; Daynac et al., 2013; Codega et al., 2014; Mich et al., 2014; Llorens-Bobadilla et al., 2015; Chaker et al., 2016; Morizur et al., 2018). Transcriptome analyses have helped to disclose the integration of signals from the microenvironment that actively maintain the quiescent state. Not surprisingly, a very significant contribution of molecules involved in cell adhesion and interaction with the niche milleu have been found to actively maintain dormancy. Amongst the most represented GO categories in qNSC are cell-cell adhesion, ECM-response and anchorage-dependent niche signals, cell communication, and signaling receptors. Most genes enriched in qNSC encoded membrane-associated proteins, underscoring the key role played by the microenvironment in the regulation of the quiescent state in the adult SEZ. Of relevance, VCAM1 and $\mathrm{N}$-cadherin previously reported as regulators of NSC quiescence

\section{REFERENCES}

Barnabe-Heider, F., Meletis, K., Eriksson, M., Bergmann, O., Sabelstrom, H., Harvey, M. A., et al. (2008). Genetic manipulation of adult mouse neurogenic niches by in vivo electroporation. Nat. Methods 5, 189-196. doi: 10.1038/nmeth. 1174

Basak, O., Krieger, T. G., Muraro, M. J., Wiebrands, K., Stange, D. E., FriasAldeguer, J., et al. (2018). Troy+ brain stem cells cycle through quiescence and
(Kokovay et al., 2012; Porlan et al., 2014) were specifically found increased in prospectively isolated qNSC, as well as other cadherins, protocadherins, neural cell adhesion molecule $1 / 2$ and ECM-components, whereas syndecan-1 was overexpressed specifically in aNSC (Morizur et al., 2018) as previously described (Kazanis et al., 2010). Interestingly, syndecans play their functions as cell surface receptors by acting as both adhesion and docking receptors, and thus are capable of regulating both intra- and extracellular activities and can recruit soluble growth factors, matrix metalloproteinases, chemokines and cytokines to the cell surface (Kwon et al., 2012) (Figure 2).

\section{CONCLUDING REMARKS}

Within the SEZ niche ecosystem, NSC necessarily communicate with their neighboring cellular populations and surrounding matrix, and such interaction is essential for the maintenance of stem cell identity and control of the timing and mode of cell division. Indeed, cell-to-cell contacts and cell-ECM adhesion not only provide tissue integrity, cell orientation and topology, but actively foster NSC self-renewal and maintenance by either placing stem cells in proximity of different signaling sources, or directly participating in the signaling process, since most adhesion molecules act as receptors and signal transductors. Many of the signaling cues that maintain NSC positioning, and some of the molecular mechanisms that trigger the switch from dormancy toward proliferation in physiological and pathological conditions to promote tissue regeneration, are starting to emerge. Amongst these, ECM and cell adhesion molecules play a crucial role, highlighting that the niche allows a relative plasticity whose manipulation provides an important window for regeneration.

\section{AUTHOR CONTRIBUTIONS}

EP conceived the manuscript. EP and JMM-R wrote the manuscript.

\section{FUNDING}

This work was funded by the Spanish MINECO grants SAF201567756R, RYC2014-15591, and FEDER to EP.

\section{ACKNOWLEDGMENTS}

We are indebted to all the cited authors for their work.

regulate their number by sensing niche occupancy. Proc. Natl. Acad. Sci. U.S.A. 115, E610-E619. doi: 10.1073/pnas.1715911114

Bast, L., Calzolari, F., Strasser, M. K., Hasenauer, J., Theis, F. J., Ninkovic, J., et al. (2018). Increasing neural stem cell division asymmetry and quiescence are predicted to contribute to the age-related decline in neurogenesis. Cell Rep. 25, 3231.e8-3240.e8. doi: 10.1016/j.celrep.2018.11.088

Beckervordersandforth, R., Tripathi, P., Ninkovic, J., Bayam, E., Lepier, A., Stempfhuber, B., et al. (2010). In vivo fate mapping and expression analysis 
reveals molecular hallmarks of prospectively isolated adult neural stem cells. Cell Stem Cell 7, 744-758. doi: 10.1016/j.stem.2010.11.017

Belvindrah, R., Graus-Porta, D., Goebbels, S., Nave, K. A., and Muller, U. (2007). Betal integrins in radial glia but not in migrating neurons are essential for the formation of cell layers in the cerebral cortex. J. Neurosci. 27, 13854-13865. doi: 10.1523/jneurosci.4494-07.2007

Bouab, M., Paliouras, G. N., Aumont, A., Forest-Berard, K., and Fernandes, K. J. (2011). Aging of the subventricular zone neural stem cell niche: evidence for quiescence-associated changes between early and mid-adulthood. Neuroscience 173, 135-149. doi: 10.1016/j.neuroscience.2010.11.032

Campos, L. S., Leone, D. P., Relvas, J. B., Brakebusch, C., Fassler, R., Suter, U., et al. (2004). Betal integrins activate a MAPK signalling pathway in neural stem cells that contributes to their maintenance. Development 131, 3433-3444. doi: $10.1242 /$ dev. 01199

Capela, A., and Temple, S. (2002). LeX/ssea-1 is expressed by adult mouse CNS stem cells, identifying them as nonependymal. Neuron $35,865-875$. doi: 10 . 1016/s0896-6273(02)00835-8

Chaker, Z., Codega, P., and Doetsch, F. (2016). A mosaic world: puzzles revealed by adult neural stem cell heterogeneity. Wiley Interdiscip. Rev. Dev. Biol. 5, 640-658. doi: 10.1002/wdev.248

Chou, F. S., Li, R., and Wang, P. S. (2018). Molecular components and polarity of radial glial cells during cerebral cortex development. Cell. Mol. Life Sci. 75, 1027-1041. doi: 10.1007/s00018-017-2680-0

Codega, P., Silva-Vargas, V., Paul, A., Maldonado-Soto, A. R., Deleo, A. M., Pastrana, E., et al. (2014). Prospective identification and purification of quiescent adult neural stem cells from their in vivo niche. Neuron 82, 545-559. doi: 10.1016/j.neuron.2014.02.039

Daynac, M., Chicheportiche, A., Pineda, J. R., Gauthier, L. R., Boussin, F. D., and Mouthon, M. A. (2013). Quiescent neural stem cells exit dormancy upon alteration of GABAAR signaling following radiation damage. Stem Cell Res. 11, 516-528. doi: 10.1016/j.scr.2013.02.008

Doetsch, F. (2003). The glial identity of neural stem cells. Nat. Neurosci. 6, 1127-1134. doi: 10.1038/nn1144

Doetsch, F., Verdugo, J. M., Caille, I., Alvarez-Buylla, A., Chao, M. V., and Casaccia-Bonnefil, P. (2002). Lack of the cell-cycle inhibitor p27Kip1 results in selective increase of transit-amplifying cells for adult neurogenesis. J. Neurosci. 22, 2255-2264. doi: 10.1523/jneurosci.22-06-02255.2002

Douet, V., Arikawa-Hirasawa, E., and Mercier, F. (2012). Fractone-heparan sulfates mediate BMP-7 inhibition of cell proliferation in the adult subventricular zone. Neurosci. Lett. 528, 120-125. doi: 10.1016/j.neulet.2012.08.077

Ferron, S. R., Charalambous, M., Radford, E., McEwen, K., Wildner, H., Hind, E., et al. (2011). Postnatal loss of Dlk1 imprinting in stem cells and niche astrocytes regulates neurogenesis. Nature 475, 381-385. doi: 10.1038/nature10229

Fietz, S. A., Kelava, I., Vogt, J., Wilsch-Brauninger, M., Stenzel, D., Fish, J. L., et al. (2010). OSVZ progenitors of human and ferret neocortex are epithelial-like and expand by integrin signaling. Nat. Neurosci. 13, 690-699. doi: 10.1038/nn.2553

Fietz, S. A., Lachmann, R., Brandl, H., Kircher, M., Samusik, N., Schroder, R., et al. (2012). Transcriptomes of germinal zones of human and mouse fetal neocortex suggest a role of extracellular matrix in progenitor self-renewal. Proc. Natl. Acad. Sci. U.S.A. 109, 11836-11841. doi: 10.1073/pnas.1209647109

Fuentealba, L. C., Rompani, S. B., Parraguez, J. I., Obernier, K., Romero, R., Cepko, C. L., et al. (2015). Embryonic origin of postnatal neural stem cells. Cell 161, 1644-1655. doi: 10.1016/j.cell.2015.05.041

Furutachi, S., Miya, H., Watanabe, T., Kawai, H., Yamasaki, N., Harada, Y., et al. (2015). Slowly dividing neural progenitors are an embryonic origin of adult neural stem cells. Nat. Neurosci. 18, 657-665. doi: 10.1038/nn.3989

Garcion, E., Faissner, A., and ffrench-Constant, C. (2001). Knockout mice reveal a contribution of the extracellular matrix molecule tenascin- $\mathrm{C}$ to neural precursor proliferation and migration. Development 128, 2485-2496.

Gil-Sanz, C., Landeira, B., Ramos, C., Costa, M. R., and Muller, U. (2014). Proliferative defects and formation of a double cortex in mice lacking Mltt 4 and Cdh2 in the dorsal telencephalon. J. Neurosci. 34, 10475-10487. doi: 10.1523/ JNEUROSCI.1793-14.2014

Graus-Porta, D., Blaess, S., Senften, M., Littlewood-Evans, A., Damsky, C., Huang, Z., et al. (2001). Beta1-class integrins regulate the development of laminae and folia in the cerebral and cerebellar cortex. Neuron 31, 367-379. doi: 10.1016/ s0896-6273(01)00374-9
Guerra, M. M., Henzi, R., Ortloff, A., Lichtin, N., Vio, K., Jimenez, A. J., et al. (2015). Cell junction pathology of neural stem cells is associated with ventricular zone disruption, hydrocephalus, and abnormal neurogenesis. J. Neuropathol. Exp. Neurol. 74, 653-671. doi: 10.1097/NEN.0000000000000203

Hirano, S., and Takeichi, M. (2012). Cadherins in brain morphogenesis and wiring. Physiol. Rev. 92, 597-634. doi: 10.1152/physrev.00014.2011

Humphries, J. D., Byron, A., and Humphries, M. J. (2006). Integrin ligands at a glance. J. Cell Sci. 119, 3901-3903. doi: 10.1242/jcs.03098

Ishibashi, S., Kuroiwa, T., Sakaguchi, M., Sun, L., Kadoya, T., Okano, H., et al. (2007). Galectin-1 regulates neurogenesis in the subventricular zone and promotes functional recovery after stroke. Exp. Neurol. 207, 302-313. doi: 10. 1016/j.expneurol.2007.06.024

Jossin, Y., Lee, M., Klezovitch, O., Kon, E., Cossard, A., Lien, W. H., et al. (2017). Llgll connects cell polarity with cell-cell adhesion in embryonic neural stem cells. Dev. Cell 41, 481-495.e5. doi: 10.1016/j.devcel.2017.05.002

Kadowaki, M., Nakamura, S., Machon, O., Krauss, S., Radice, G. L., and Takeichi, M. (2007). N-cadherin mediates cortical organization in the mouse brain. Dev. Biol. 304, 22-33. doi: 10.1016/j.ydbio.2006.12.014

Kalamakis, G., Brune, D., Ravichandran, S., Bolz, J., Fan, W., Ziebell, F., et al. (2019). Quiescence modulates stem cell maintenance and regenerative capacity in the aging brain. Cell 176, 1407-1419.e14. doi: 10.1016/j.cell.2019. 01.040

Karpowicz, P., Willaime-Morawek, S., Balenci, L., DeVeale, B., Inoue, T., and van der Kooy, D. (2009). E-Cadherin regulates neural stem cell self-renewal. J. Neurosci. 29, 3885-3896. doi: 10.1523/JNEUROSCI.0037-09.2009

Kawaguchi, D., Furutachi, S., Kawai, H., Hozumi, K., and Gotoh, Y. (2013). Dll1 maintains quiescence of adult neural stem cells and segregates asymmetrically during mitosis. Nat. Commun. 4:1880. doi: 10.1038/ncomms 2895

Kazanis, I., Belhadi, A., Faissner, A., and Ffrench-Constant, C. (2007). The adult mouse subependymal zone regenerates efficiently in the absence of tenascin-C. J. Neurosci. 27, 13991-13996. doi: 10.1523/jneurosci.3279-07.2007

Kazanis, I., Lathia, J. D., Vadakkan, T. J., Raborn, E., Wan, R., Mughal, M. R., et al. (2010). Quiescence and activation of stem and precursor cell populations in the subependymal zone of the mammalian brain are associated with distinct cellular and extracellular matrix signals. J. Neurosci. 30, 9771-9781. doi: 10. 1523/jneurosci.0700-10.2010

Kerever, A., Schnack, J., Vellinga, D., Ichikawa, N., Moon, C., Arikawa-Hirasawa, E., et al. (2007). Novel extracellular matrix structures in the neural stem cell niche capture the neurogenic factor fibroblast growth factor 2 from the extracellular milieu. Stem Cells 25, 2146-2157. doi: 10.1634/stemcells.20070082

Kippin, T. E., Martens, D. J., and van der Kooy, D. (2005). p21 loss compromises the relative quiescence of forebrain stem cell proliferation leading to exhaustion of their proliferation capacity. Genes Dev. 19, 756-767. doi: 10.1101/gad.1272305

Klingener, M., Chavali, M., Singh, J., McMillan, N., Coomes, A., Dempsey, P. J., et al. (2014). N-cadherin promotes recruitment and migration of neural progenitor cells from the SVZ neural stem cell niche into demyelinated lesions. J. Neurosci. 34, 9590-9606. doi: 10.1523/JNEUROSCI.3699-13.2014

Kokovay, E., Goderie, S., Wang, Y., Lotz, S., Lin, G., Sun, Y., et al. (2010). Adult SVZ lineage cells home to and leave the vascular niche via differential responses to SDF1/CXCR4 signaling. Cell Stem Cell 7, 163-173. doi: 10.1016/j.stem.2010. 05.019

Kokovay, E., Wang, Y., Kusek, G., Wurster, R., Lederman, P., Lowry, N., et al. (2012). VCAM1 is essential to maintain the structure of the SVZ niche and acts as an environmental sensor to regulate SVZ lineage progression. Cell Stem Cell 11, 220-230. doi: 10.1016/j.stem.2012.06.016

Kriegstein, A., and Alvarez-Buylla, A. (2009). The glial nature of embryonic and adult neural stem cells. Annu. Rev. Neurosci. 32, 149-184. doi: 10.1146/annurev. neuro.051508.135600

Kwon, M.-J., Jang, B., Yi, J. Y., Han, I.-O., and Oh, E. S. (2012). Syndecans play dual roles as cell adhesion receptors and docking receptors. FEBS Lett. 586, 2207-2211. doi: 10.1016/j.febslet.2012.05.037

Lathia, J. D., Patton, B., Eckley, D. M., Magnus, T., Mughal, M. R., Sasaki, T., et al. (2007). Patterns of laminins and integrins in the embryonic ventricular zone of the CNS. J. Comp. Neurol. 505, 630-643. doi: 10.1002/cne.21520

Lim, D. A., and Alvarez-Buylla, A. (2014). Adult neural stem cells stake their ground. Trends Neurosci. 37, 563-571. doi: 10.1016/j.tins.2014.08.006 
Lin, R., and Iacovitti, L. (2015). Classic and novel stem cell niches in brain homeostasis and repair. Brain Res. 1628(Pt B), 327-342. doi: 10.1016/j.brainres. 2015.04.029

Llorens-Bobadilla, E., and Martin-Villalba, A. (2017). Adult NSC diversity and plasticity: the role of the niche. Curr. Opin. Neurobiol. 42, 68-74. doi: 10.1016/j. conb.2016.11.008

Llorens-Bobadilla, E., Zhao, S., Baser, A., Saiz-Castro, G., Zwadlo, K., and MartinVillalba, A. (2015). Single-cell transcriptomics reveals a population of dormant neural stem cells that become activated upon brain injury. Cell Stem Cell 17, 329-340. doi: 10.1016/j.stem.2015.07.002

Loulier, K., Lathia, J. D., Marthiens, V., Relucio, J., Mughal, M. R., Tang, S. C., et al. (2009). betal integrin maintains integrity of the embryonic neocortical stem cell niche. PLoS Biol. 7:e1000176. doi: 10.1371/journal.pbio.1000176

Luo, J., Daniels, S. B., Lennington, J. B., Notti, R. Q., and Conover, J. C. (2006). The aging neurogenic subventricular zone. Aging Cell 5, 139-152. doi: 10.1111/ j.1474-9726.2006.00197.x

Marques-Torrejon, M. A., Porlan, E., Banito, A., Gomez-Ibarlucea, E., LopezContreras, A. J., Fernandez-Capetillo, O., et al. (2013). Cyclin-dependent kinase inhibitor p21 controls adult neural stem cell expansion by regulating Sox 2 gene expression. Cell Stem Cell 12, 88-100. doi: 10.1016/j.stem.2012.12.001

Marthiens, V., Kazanis, I., Moss, L., Long, K., and Ffrench-Constant, C. (2010). Adhesion molecules in the stem cell niche-more than just staying in shape? J. Cell Sci. 123(Pt 10), 1613-1622. doi: 10.1242/jcs.054312

Meng, W., and Takeichi, M. (2009). Adherens junction: molecular architecture and regulation. Cold Spring Harb. Perspect. Biol. 1:a002899. doi: 10.1101/ cshperspect.a002899

Menn, B., Garcia-Verdugo, J. M., Yaschine, C., Gonzalez-Perez, O., Rowitch, D., and Alvarez-Buylla, A. (2006). Origin of oligodendrocytes in the subventricular zone of the adult brain. J. Neurosci. 26, 7907-7918. doi: 10.1523/jneurosci.129906.2006

Mercier, F., and Douet, V. (2014). Bone morphogenetic protein-4 inhibits adult neurogenesis and is regulated by fractone-associated heparan sulfates in the subventricular zone. J. Chem. Neuroanat. 5, 54-61. doi: 10.1016/j.jchemneu. 2014.03.005

Mercier, F., Kitasako, J. T., and Hatton, G. I. (2002). Anatomy of the brain neurogenic zones revisited: fractones and the fibroblast/macrophage network. J. Comp. Neurol. 451, 170-188. doi: 10.1002/cne.10342

Merkle, F. T., Fuentealba, L. C., Sanders, T. A., Magno, L., Kessaris, N., and Alvarez-Buylla, A. (2014). Adult neural stem cells in distinct microdomains generate previously unknown interneuron types. Nat. Neurosci. 17, 207-214. doi: $10.1038 / \mathrm{nn} .3610$

Merkle, F. T., Tramontin, A. D., Garcia-Verdugo, J. M., and Alvarez-Buylla, A. (2004). Radial glia give rise to adult neural stem cells in the subventricular zone. Proc. Natl. Acad. Sci. U.S.A. 101, 17528-17532. doi: 10.1073/pnas.0407893101

Mich, J. K., Signer, R. A., Nakada, D., Pineda, A., Burgess, R. J., Vue, T. Y., et al. (2014). Prospective identification of functionally distinct stem cells and neurosphere-initiating cells in adult mouse forebrain. eLife 3:e02669. doi: 10. 7554/eLife.02669

Mirzadeh, Z., Merkle, F. T., Soriano-Navarro, M., Garcia-Verdugo, J. M., and Alvarez-Buylla, A. (2008). Neural stem cells confer unique pinwheel architecture to the ventricular surface in neurogenic regions of the adult brain. Cell Stem Cell 3, 265-278. doi: 10.1016/j.stem.2008.07.004

Miyamoto, Y., Sakane, F., and Hashimoto, K. (2015). N-cadherin-based adherens junction regulates the maintenance, proliferation, and differentiation of neural progenitor cells during development. Cell Adh. Migr. 9, 183-192. doi: 10.1080/ 19336918.2015.1005466

Mobley, A. K., and McCarty, J. H. (2011). beta8 integrin is essential for neuroblast migration in the rostral migratory stream. Glia 59, 1579-1587. doi: 10.1002/glia. 21199

Mobley, A. K., Tchaicha, J. H., Shin, J., Hossain, M. G., and McCarty, J. H. (2009). Beta8 integrin regulates neurogenesis and neurovascular homeostasis in the adult brain. J. Cell Sci. 122(Pt 11), 1842-1851. doi: 10.1242/jcs. 043257

Molofsky, A. V., He, S., Bydon, M., Morrison, S. J., and Pardal, R. (2005). Bmi1 promotes neural stem cell self-renewal and neural development but not mouse growth and survival by repressing the p16Ink4a and p19Arf senescence pathways. Genes Dev. 19, 1432-1437. doi: 10.1101/gad.1299505
Molofsky, A. V., Pardal, R., Iwashita, T., Park, I. K., Clarke, M. F., and Morrison, S. J. (2003). Bmi-1 dependence distinguishes neural stem cell self-renewal from progenitor proliferation. Nature 425, 962-967. doi: 10.1038/nature02060

Molofsky, A. V., Slutsky, S. G., Joseph, N. M., He, S., Pardal, R., Krishnamurthy, J., et al. (2006). Increasing p16INK4a expression decreases forebrain progenitors and neurogenesis during ageing. Nature 443, 448-452. doi: 10.1038/ nature05091

Morgan, M. R., Humphries, M. J., and Bass, M. D. (2007). Synergistic control of cell adhesion by integrins and syndecans. Nat. Rev. Mol. Cell Biol. 8, 957-969. doi: $10.1038 / \mathrm{nrm} 2289$

Morizur, L., Chicheportiche, A., Gauthier, L. R., Daynac, M., Boussin, F. D., and Mouthon, M. A. (2018). Distinct molecular signatures of quiescent and activated adult neural stem cells reveal specific interactions with their microenvironment. Stem Cell Rep. 11, 565-577. doi: 10.1016/j.stemcr.2018. 06.005

Nascimento, M. A., Sorokin, L., and Coelho-Sampaio, T. (2018). Fractone bulbs derive from ependymal cells and their laminin composition influence the stem cell niche in the subventricular zone. J. Neurosci. 38, 3880-3889. doi: 10.1523/ jneurosci.3064-17.2018

Ortega, F., Gascon, S., Masserdotti, G., Deshpande, A., Simon, C., Fischer, J., et al. (2013). Oligodendrogliogenic and neurogenic adult subependymal zone neural stem cells constitute distinct lineages and exhibit differential responsiveness to Wnt signalling. Nat. Cell Biol. 15, 602-613. doi: 10.1038/ncb2736

Ottone, C., Krusche, B., Whitby, A., Clements, M., Quadrato, G., Pitulescu, M. E., et al. (2014). Direct cell-cell contact with the vascular niche maintains quiescent neural stem cells. Nat. Cell Biol. 16, 1045-1056. doi: 10.1038/ncb3045

Paez-Gonzalez, P., Abdi, K., Luciano, D., Liu, Y., Soriano-Navarro, M., Rawlins, E., et al. (2011). Ank3-dependent SVZ niche assembly is required for the continued production of new neurons. Neuron 71, 61-75. doi: 10.1016/j.neuron.2011. 05.029

Pan, L., North, H. A., Sahni, V., Jeong, S. J., McGuire, T. L., Berns, E. J., et al. (2014). betal-Integrin and integrin linked kinase regulate astrocytic differentiation of neural stem cells. PLoS One 9:e104335. doi: 10.1371/journal.pone.0104335

Pastrana, E., Cheng, L. C., and Doetsch, F. (2009). Simultaneous prospective purification of adult subventricular zone neural stem cells and their progeny. Proc. Natl. Acad. Sci. U.S.A. 106, 6387-6392. doi: 10.1073/pnas.0810407106

Ponti, G., Obernier, K., Guinto, C., Jose, L., Bonfanti, L., and Alvarez-Buylla, A. (2013). Cell cycle and lineage progression of neural progenitors in the ventricular-subventricular zones of adult mice. Proc. Natl. Acad. Sci. U.S.A. 110, E1045-E1054. doi: 10.1073/pnas.1219563110

Porcheri, C., Suter, U., and Jessberger, S. (2014). Dissecting integrin-dependent regulation of neural stem cell proliferation in the adult brain. J. Neurosci. 34, 5222-5232. doi: 10.1523/jneurosci.4928-13.2014

Porlan, E., Marti-Prado, B., Morante-Redolat, J. M., Consiglio, A., Delgado, A. C., Kypta, R., et al. (2014). MT5-MMP regulates adult neural stem cell functional quiescence through the cleavage of N-cadherin. Nat. Cell Biol. 16, 629-638. doi: $10.1038 /$ ncb2993

Porlan, E., Morante-Redolat, J. M., Marques-Torrejon, M. A., Andreu-Agullo, C., Carneiro, C., Gomez-Ibarlucea, E., et al. (2013). Transcriptional repression of Bmp2 by $\mathrm{p} 21$ (Waf1/Cip1) links quiescence to neural stem cell maintenance. Nat. Neurosci. 16, 1567-1575. doi: 10.1038/nn.3545

Radice, P. D., Mathieu, P., Leal, M. C., Farias, M. I., Ferrari, C., Puntel, M., et al. (2015). Fibulin-2 is a key mediator of the pro-neurogenic effect of TGF-betal on adult neural stem cells. Mol. Cell Neurosci. 67, 75-83. doi: 10.1016/j.mcn. 2015.06.004

Rosa, A. I., Grade, S., Santos, S. D., Bernardino, L., Chen, T. C., Relvas, J., et al. (2016). Heterocellular contacts with mouse brain endothelial cells via laminin and alpha6betal integrin sustain subventricular zone (SVZ) stem/progenitor cells properties. Front. Cell Neurosci. 10:284. doi: 10.3389/fncel.2016.00284

Sakaguchi, M., Imaizumi, Y., Shingo, T., Tada, H., Hayama, K., Yamada, O., et al. (2010). Regulation of adult neural progenitor cells by galectin-1/betal integrin interaction. J. Neurochem. 113, 1516-1524. doi: 10.1111/j.1471-4159. 2010.06712.x

Sakaguchi, M., Shingo, T., Shimazaki, T., Okano, H. J., Shiwa, M., Ishibashi, S., et al. (2006). A carbohydrate-binding protein, Galectin-1, promotes proliferation of adult neural stem cells. Proc. Natl. Acad. Sci. U.S.A. 103, 7112-7117. doi: 10. 1073/pnas.0508793103 
Sato, Y., Kiyozumi, D., Futaki, S., Nakano, I., Shimono, C., Kaneko, N., et al. (2019). Ventricular-subventricular zone fractones are speckled basement membranes that function as a neural stem cell niche. Mol. Biol. Cell 30, 56-68. doi: 10.1091/ mbc.E18-05-0286

Scadden, D. T. (2006). The stem-cell niche as an entity of action. Nature 441, 1075-1079. doi: 10.1038/nature04957

Shan, X., Tomlinson, L., Yang, Q., and Colognato, H. (2018). Distinct requirements for extracellular and intracellular MMP12 in the development of the adult V-SVZ neural stem cell niche. Stem Cell Rep. 10, 984-999. doi: 10.1016/j.stemcr. 2018.01.038

Shen, Q., Wang, Y., Kokovay, E., Lin, G., Chuang, S. M., Goderie, S. K., et al. (2008). Adult SVZ stem cells lie in a vascular niche: a quantitative analysis of niche cell-cell interactions. Cell Stem Cell 3, 289-300. doi: 10.1016/j.stem.2008. 07.026

Silva-Vargas, V., Maldonado-Soto, A. R., Mizrak, D., Codega, P., and Doetsch, F. (2016). Age-dependent niche signals from the choroid plexus regulate adult neural stem cells. Cell Stem Cell 19, 643-652. doi: 10.1016/j.stem.2016. 06.013

Sohn, J., Orosco, L., Guo, F., Chung, S. H., Bannerman, P., Mills Ko, E., et al. (2015). The subventricular zone continues to generate corpus callosum and rostral migratory stream astroglia in normal adult mice. J. Neurosci. 35, 3756-3763. doi: 10.1523/jneurosci.3454-14.2015
Tavazoie, M., Van der Veken, L., Silva-Vargas, V., Louissaint, M., Colonna, L., Zaidi, B., et al. (2008). A specialized vascular niche for adult neural stem cells. Cell Stem Cell 3, 279-288. doi: 10.1016/j.stem.2008.07.025

Theocharidis, U., Long, K., ffrench-Constant, C., and Faissner, A. (2014). Regulation of the neural stem cell compartment by extracellular matrix constituents. Prog. Brain Res. 214, 3-28. doi: 10.1016/B978-0-444-63486-3. 00001-3

Tramontin, A. D., Garcia-Verdugo, J. M., Lim, D. A., and Alvarez-Buylla, A. (2003). Postnatal development of radial glia and the ventricular zone (VZ): a continuum of the neural stem cell compartment. Cereb. Cortex 13, 580-587. doi: $10.1093 /$ cercor/13.6.580

Conflict of Interest Statement: The authors declare that the research was conducted in the absence of any commercial or financial relationships that could be construed as a potential conflict of interest.

Copyright (c) 2019 Morante-Redolat and Porlan. This is an open-access article distributed under the terms of the Creative Commons Attribution License (CC BY). The use, distribution or reproduction in other forums is permitted, provided the original author(s) and the copyright owner(s) are credited and that the original publication in this journal is cited, in accordance with accepted academic practice. No use, distribution or reproduction is permitted which does not comply with these terms. 